\title{
LA VISIÓN PREMONITORIA DE ALONSO EN EL CABALLERO DE OLMEDO: OTRA RECUPERACIÓN DE LO POPULAR
}

\author{
David GonzÁlez de la Higuera GarRido \\ Universidad Complutense de Madrid \\ d2avi3d2.dgh@hotmail.com
}

$\mathrm{L}$

ope de Vega, como sus contemporáneos que empezaban a escribir hacia 1580 , tenía una fuerte deuda con la poesía popular, solo que en su caso no se contentó únicamente con componer un gran corpus de romances nuevos, sino que también adaptó una gran parte de esa tradición en el teatro, de manera similar a como lo hizo Gil Vicente (Palomo 1987: 44) ${ }^{1}$. No obstante, de todas las composiciones teatrales de nuestro autor, debemos considerar a El caballero de Olmedo (1620) como eminentemente popular, ya que nace de una cancioncilla consabida por el pueblo y por la crítica: «Que de noche le mataron / al Caballero, / la gala de Medina, / la flor de Olmedo» ${ }^{2}$. Esta comedia, por ello, presenta tal

1 El género del romancero nuevo, popularizado en las postrimerías del siglo xvI, solamente fue posible gracias al enorme éxito que disfrutaban las colecciones de romances tradicionales por aquella época. Los trabajos de Rodríguez-Moñino $(1957,1967)$ son importantes a este respecto, aunque para la cultivación del romancero nuevo en Lope de Vega resulta indispensable el libro de Antonio Carreño (1979). Este estudio, pese a que no se centre en el estilo romancístico de su teatro, que no considera equiparable al romancero lirico, sí que introduce la concepción de nuestro autor acerca del romance, relacionable hasta cierto punto con su teatro, pues aúna el artificio lírico con la narración de hechos determinados: «asienta pues Lope la definición del romance como punto intermedio entre la canción lírica y la exposición prosificada; entre la melodía uniforme y la narración» (1979: 18).

2 Las fuentes de esta obra lopesca son estudiadas escrupulosamente en la edición preparada por Francisco Rico, quien habla de esta seguidilla de forma detallada (Vega Carpio 2011: 4852), aunque considera que las bases de este drama se asientan en un romance más antiguo no conservado: «creo sumamente probable que existiera un romance centrado en la muerte sangrienta de don Juan [de Vivero] y en el cual se recogieran todos los elementos en que concuerdan los hechos de 1521 y las recreaciones artísticas del primer cuarto del siglo XVII» (2011: 41). Sage no está conforme con esa teoría, ya que considera que las influencias no están suficientemente verificadas: «there is no evidence whatsoever for believing that El caballero de Olmedo by Lope, or any of the known versions, is based upon this sixteenth-century song» (Vega Carpio 1974: 15).

Edad de Oro, XXXIV (2015), pp. 157-168, ISSN: 0212-0429 - DOI http://dx.doi.org/10.15366/edadoro2015.34.010 
fuerza dramática y misterio; la familiaridad que percibía el público constituía una atracción segura, pero a la vez un problema que el buen dramaturgo tenía que solucionar, mediante la utilización concienzuda del lirismo y el simbolismo para conseguir sorprender al espectador que conocía la historia (Pedraza 2008: 179). La insistencia en lo popular, específicamente en esta pieza teatral, supone la evidencia de un cambio en las tablas desde finales del XVI, donde las técnicas cultas rinden homenaje a las formas más genuinas de la lírica tradicional, con Lope de Vega a la cabeza y todo un séquito de dramaturgos que le siguen muy de cerca.

Aunque ya se haya estudiado con detenimiento las piezas populares incrustadas en las comedias lopescas (Díez de Revenga 1983), falta a día de hoy un escrito donde se pase revista a los temas o tópicos tradicionales insertos en la comedia como si fueran de estilo elevado y culto. Desde luego, Lope de Vega se servía de elementos naturales y animales como actantes del sentimiento amoroso, costumbre registrada en la lírica tradicional; no obstante, las filiaciones a lo popular no siempre son tan claras ${ }^{3}$. Por esta razón, he decidido presentar aquí el estudio del pasaje del sueño de Alonso como ejemplo de esta asimilación de conceptos populares, pero tamizados por un quehacer poético preciosista y relacionado con presupuestos más elevados ${ }^{4}$. Veamos, pues, en qué consiste este fragmento situado en el final del segundo acto:

Hoy, Tello, al salir el alba, con la inquietud de la noche, me levanté de la cama, abrí la ventana aprisa, $\mathrm{y}$, mirando flores y aguas que adornan nuestro jardín, sobre una verde retama veo ponerse un jilguero, cuyas esmaltadas alas, con lo amarillo añadían flores a las verdes ramas. $\mathrm{Y}$ estando al aire trinando

Para el teatro de Lope y su bibliografía fundamental, remito al estudio que hace Juan Manuel Rozas (1990: 37-58).

3 Margit Frenk estudia El castigo sin venganza a partir del análisis de las metáforas relacionadas con el mundo animal, con el objetivo de desentrañar los entresijos del estilo de la comedia lopesca, no sin antes constatar la dificultad de esta labor: «Lope de Vega supo fundir los varios niveles en un todo compacto, en que nada falta y nada sobra, un todo regido, de principio a fin, por una concepción unitaria» (2007: 68). Véase también, sobre Lope y la lírica tradicional, un artículo de la misma autora (1963), y un trabajo de Zamora Vicente (1986).

4 Este rasgo de lo onírico en la visión de Alonso es comentado superficialmente en la edición de Ignacio Arellano y de Manuel Escudero: «y es que el territorio de lo real y lo onírico se relacionan en un continuo poético indefinido» (1998: 66). 
de la pequeña garganta

con naturales pasajes

las quejas enamoradas, sale un azor de un almendro, adonde escondido estaba, y como eran en los dos tan desiguales las armas, tiñó de sangre las flores, plumas al aire derrama. Al triste chillido, Tello, débiles ecos del aura, respondieron, y, no lejos, lamentando su desgracia, su esposa, que en un jazmín la tragedia viendo estaba.

(Vega Carpio 2011: 169-170, vv. 1757-1783)

La visión (o el sueño) que profetiza el final trágico de esta comedia se configura a base de elementos típicamente populares, pero elaborados desde una vertiente culta que tiene muy presente tanto la tradición petrarquista italiana como la castellana cancioneril, aunque siempre dentro de los parámetros de sencillez en el ornato a que nos tiene acostumbrados ${ }^{5}$. Para empezar, la forma métrica del fragmento motiva tanto a la fidelidad en materia popular como a la utilización de recursos estilísticos no tan rebuscados conceptualmente, aunque existía cierta reticencia al estilo del romancero viejo por parte de los poetas cultos. De este modo, solamente se abogaba por una recuperación de metros populares para llenarlos de «concepto», de forma que se hacían composiciones artificiosas e ingeniosas que quedan muy lejos de la esencia de la poesía popular que pretendía reflejar Lope de Vega en sus comedias 6.

Desde luego, esto no supone ninguna novedad, si pensamos en la defensa que hace Lope de Vega del arte natural en oposición al culto, porque este no es fiel a la vida misma. Por otra parte, el uso de las distintas formas métricas en el teatro

5 José Manuel Blecua afirma en su monografía sobre la poesía de los siglos de oro (1970) que existen cuatro corrientes que definen la poesía del siglo xvi: la lírica tradicional, el romancero, la poesía culta cuatrocentista y el Cancionero general (1970: 11-24). Desde esta perspectiva, se nos presenta la preocupación por mezclar lo culto con lo popular, que es lo que se propone Lope en escena.

6 El cisne de Apolo de Luis Alfonso de Carvallo, por ejemplo, define el romance como una forma de trovar necesariamente culta, lo que reproduzco con la ortografía moderna y la puntuación retocadas por mí: «Porque la principal gracia del romance está en la tonada [...] Tiene demás de esto el romance necesidad más que otra [de] compostura, de atavío, galantería, y ornato, y ser adornado y enriquecido con muchas sentencias, figuras, y conceptos, y natural gracia, porque sin esto, quienquiera hará romances de Condeclaros...» (1602: ff. 78v-79r). 
viene prefigurado en el Arte nuevo de hacer comedias en estos tiempos (1609), donde se señala a la métrica romancística como aquella idónea para introducir relaciones e historias contadas por los personajes mediante esta breve sentencia: «las relaciones piden los romances» (Vega Carpio 2012b: 148, v. 309). Sin embargo, según Diego Marín en su prólogo a La dama boba, donde también se repasan presupuestos básicos del «arte nuevo», el uso del romance se extiende a lo largo de la evolución artística del dramaturgo a los diálogos y a los finales de cada acto $^{7}$. De esta segunda forma es como se puede observar el uso del romance en $E l$ caballero de Olmedo, una obra que se sitúa en el periodo de senectud de Lope de $\mathrm{Vega}^{8}$. Aun con todo, la elección de la asonancia en $a-a$, junto con la apuesta por un estilo depurado y sencillo, sitúan a nuestro dramaturgo como un defensor del arte popular; pero estudiemos más detenidamente los elementos que constituyen el pasaje y que podemos considerar también como signos de esta vertiente poética y cultural perteneciente a nuestro folklore.

En primer lugar, que la visión de Alonso se desarrolle durante el amanecer nos sitúa de lleno en la tradición de la alborada, aunque este tópico suele ir acompañado del encuentro de los amantes o, por el contrario, de su separación. Los célebres versos «al alba venid, buen amigo / al alba venid» (Frenk 2010: 93) conectan con el pasaje del sueño nada más empezar («al salir el alba», v. 1757), para luego pasar a la temática culta en el verso siguiente, donde la oscuridad de la noche se califica con el nombre solemne de «inquietud» (v. 1758), de manera que se preludia desde un principio el carácter negativo de este sueño, que bien puede calificarse como una visión. Desde los primeros versos de este fragmento, Lope es fiel a su estilo sencillo y con poco artificio de ingenio, lo que indica un fuerte rasgo de modernidad en el trato de la casuística amorosa que ya compartía el mejor petrarquismo. En este caso, decide situar el posterior encuentro amoroso durante el momento de la salida del sol, lo que indica una cierta relación con las cancioncillas dedicadas al alba y que pertenecían al terreno de la lírica tradicional, a pesar de que el episodio se desarrolle de noche. Solamente al final de la relación veremos las primeras pintadas del alba, en consonancia con los lloros de la mujer amante que contempla la muerte de su amado.

7 «[El romance] va aumentando más tarde su frecuencia y al mismo tiempo diversificando sus usos hasta quedar como metro dominante al final, reemplazando en gran parte a las redondillas y quintillas, sobre todo para el diálogo dinámico que hace progresar la acción en vez de comentarla simplemente» (Vega Carpio 1989: 22).

8 Yerra, por tanto, Sage cuando afirma que el romance sigue empleándose para relatar historias, sin destacar ninguna forma de renovación en el uso de este esquema métrico: «El caballero de Olmedo, however, is again in line with the Arte nuevo: romance is often used in passages where the emphasis is not so much on the love interest as on Lope's plot or the characters' plotting» (Vega Carpio 1974: 78). 
A continuación, nuestro personaje se dispone a describirnos una acción fatídica que tiene lugar en un jardín, una suerte de hortus conclusus compuesto por «flores y aguas» (v. 1761). Si bien conservamos en nuestra literatura una insistencia notable en el uso del jardín como lugar de intimación amorosa, sin duda se debe a la impronta del género popular, ya que el vergel, seguido de la ribera, es generalmente considerado un lugar de amores (Alín 1968: 206). Sin embargo, la escena que Alonso va a relatar no tiene nada que ver con la pérdida de la virginidad de la mujer al recoger rosas del rosal desconocido o peras del huerto ajeno, sino que decide deleitarnos con la visión de una imagen de cetrería, tópico reseñado desde la poesía de los orígenes a la de autores renacentistas como San Juan de la $\mathrm{Cruz}^{9}$. Por el momento, el paisaje que el personaje contempla desde su ventana constituye un locus amoenus donde se conjuga toda una manifestación natural, empezando por la presencia de flores y aguas, y terminando con la de los pájaros, en una suerte de episodio que preludia el trágico final de El caballero de Olmedo. Ahora bien, cada elemento que interviene en la visión de Alonso presupone un carácter simbólico determinado, además de la identificación que confiere cada uno de ellos, que debemos analizar para ver si tiene una filiación popular o si se trata de una invención propia del ingenio del dramaturgo.

Dentro del vergel que contempla, Alonso ve posarse bajo una retama un jilguero, animal famoso por su hermoso canto, y que representa simbólicamente el papel de enamorado, de forma que se identifica directamente con el observador de la escena. Normalmente, en la lírica tradicional el actante masculino suele tomar forma de ruiseñor o de papagayo, exactamente para incidir en el papel cantor del amante que también comparte el jilguero, aunque también ambas aves están muy relacionadas con la tradición del vergel de amores, pues son las más frecuentes en este tipo de composiciones ${ }^{10}$. El jilguero es un animal más difícil de encontrar en este corpus, a pesar de que comparta las mismas propiedades que esas dos aves típicas; valga, por tanto, con resaltar la majestuosidad y nobleza de esta ave cantora, cualidades que no son necesariamente compartidas por el ruiseñor o el

\footnotetext{
$9 \quad$ Sobre la lírica de Juan de Yepes y la cetrería de amor, resulta interesante mencionar el estudio de Dámaso Alonso (1964: 271-293), quien después de citar influencias anteriores en la literatura española sobre este tópico señala los antecedentes de la pieza «Tras de un amoroso lance», pues presenta la cetrería de amor hecha a lo divino.

10 Torner reproduce el poema de Alfonso XI que utilizamos para evidenciar este carácter de las dos aves: «Así como el mes de mayo, / cuando el ruiseñor canta / y responde el papagayo / de la muy fermosa planta...» (1966: 124). En La Celestina (acto XIX), Melibea entona una canción mientras espera la llegada de Calisto, donde el ruiseñor y el papagayo actúan como mensajeros de los amores de la dama, que aguarda durante el amanecer: «Papagayos, ruiseñores, / que cantáis al alborada, / llevad nueva a mis amores / cómo espero aquí asentada...» (Rojas 2008: 580-581). Este doblete rivaliza en número de apariciones con el del ruiseñor y la calandria, aunque este segundo pájaro refiera al sexo femenino en vez de al masculino. Véase un registro y comentario de dichas apariciones en McGrady (1989: 275).
} 
papagayo ${ }^{11}$. Por otro lado, el jilguero anda posado en una retama verde, arbusto que recuerda las amarguras que trae el amor, como dicen estas coplas asturianas:

De la retama la rama, de la rama la corteza; non hay cosa más amarga que amor donde no hay firmeza.

(Torner 1966: 136)

Sin embargo, las flores de esta planta, que normalmente son de color amarillo, serán puestas por las alas del jilguero, en una imagen sensorial sencilla pero con una pizca de ingenio que le hace ser claramente de raigambre culta: «veo ponerse un jilguero, / cuyas esmaltadas alas / con lo amarillo añadían / flores a las verdes ramas» (vv. 1764-1767). Aparte de la simbiosis entre los reinos animal y vegetal que demuestran estos versos, también sugieren, dentro de una concepción simbólica relacionada con el sentimiento amoroso, la total subyugación que padece el amante ante las vicisitudes del amor. Y es que la retama es el elemento vegetal perfecto para acompañar el canto lastimero del pájaro enamorado, según las connotaciones que tenía en la poesía popular. El romance sigue con una cuarteta que recrea precisamente este estado, típico en las convenciones del amor cortés medieval, incidiendo a la par en la delicadeza del jilguero, que expresa sus sentimientos con naturalidad, en tanto que se considera un ser enamorado y sufriente por ello: «Y estado al aire trinando / de la pequeña garganta / con naturales pasajes / las quejas enamoradas» (vv. 1768-1771) ${ }^{12}$. Esta sencillez en su canto, completamente contraria a las normas que regían la antigua lírica cancioneril, establece el clímax del pasaje, ya que es este canto el que acaba atrayendo a su rival, iniciándose la tragedia que luego se convierte en premonitoria: el águila, que aguardaba su oportunidad escondida en un almendro, se dispone a atacar al jilguero cuando tiene las defensas más bajas.

La constitución envidiable de esta ave de presa le hace convertirse en un depredador temido dentro del mundo animal, lo que se traduce en el texto poético exactamente del mismo modo ${ }^{13}$. En el corpus compilado por Margit Frenk

11 Sage (Vega Carpio 1974: 88) destaca la ignorancia proverbial del jilguero, que aparece explícitamente en La Arcadia (1598): «Su amiga Pradelia había puesto en un óvalo un jilguero en un ramo, asido a unas varetas de liga, con una letra que decía: Mi ignorancia» (Vega Carpio 2012a: 674).

12 Para un estudio detallado de la temática y los principios fundamentales del amor cortés, véase Green (1969: 152-194), que relaciona este tipo de amor con los postulados neoplatónicos, y Rodado Ruiz (2000), que estudia los fundamentos de esta moda literaria en la poesía de cancionero castellana.

13 En el Bestiario de amor de Fournival, el águila aparece como un animal orgulloso que debe romper su pico y afilarlo de nuevo cuando lo tiene tan grande que no puede comer con él; 
podemos observar que el águila es un agente engañador en las empresas amorosas, pues se deja seguir por sus instintos asesinos, heredados por su naturaleza de cazador; en este sentido, podemos leer en el Vocabulario de Correas (1627) este pareado popular que sirve como advertencia para las niñas inocentes: «Voz tiene el águila, niña, / voz tiene el aguililla» (Frenk 1987: 301). Empero, esta característica de ave feroz puede hacer que aparezca en composiciones donde se produzcan altercados violentos por la lucha de dos rivales; es el caso de una piececilla encontrada en la Serra da Estrela de Gil Vicente (1527), donde dos azores luchan por amores de una dama, y solamente puede quedar con vida uno de los dos:

\begin{abstract}
A mi seguem os dous açores, hum delles moriráa d'amores.

Dous açores qu'eu avia

aqui andam nesta baylia.

Hum delles moriráa d'amores.
\end{abstract}

(Frenk 1987: 161)

A diferencia del significado simbólico que pienso que contiene la retama, no considero que el almendro de donde sale el águila tenga mayores connotaciones que las de un árbol típico de los paisajes idílicos que tantas veces se reiteraban en el género pastoril durante el siglo XVI, y que rescata Lope de Vega para componer este verge ${ }^{14}$. A pesar de ello, resulta significativo que el agente violento de la escena decida esconderse entre este elemento vegetal para acechar a su presa que canta despreocupada, creando de ese modo una expectación de sorpresa que debía compartir el espectador de la época, que estaba esperando que se produjera una escena amorosa en vez de un lance por amor. Como hemos visto, la sorpresa es un rasgo fundamental en esta obra dramática, que pasa de una comedia de enredos en los dos primeros actos a una tragedia en el último (Pedraza 2008: 176). En fin, este pasaje constituye un adelanto de ese violento viraje a lo trágico, que culmina con la muerte de Alonso en el medio del camino que va desde Medina a Olmedo.

solo cuando se produce ese rompimiento, el águila muestra su sensibilidad para con el amor (Fournival 1980: 83). Aunque no aparezca esta situación en el fragmento que analizamos, considero pertinente recordar que a mediados del siglo XIII esta ave ya encarnaba la soberbia y la implacabilidad dentro del terreno amoroso.

14 En el corpus de Torner tenemos el ejemplo de la flor del almendro, que tiene una vida muy efímera como la esperanza en el amor o el amor mismo. Como no tiene interés con respecto al pasaje que estamos estudiando, solamente procedo a incluir una de las muchas piezas que recoge este compilador sobre este elemento floral: «Como flores de almendro / fueron mis bienes, / que nacieron temprano / para perderse» (1966: 118). En cambio, este árbol aparece como elemento vegetal, junto al jilguero, en un pasaje de La Arcadia: «Canta el jilguero, el verderón y el pardo / [...] / en el almendro o estéril cardo» (Vega Carpio 2012a: 484).

Edad de Oro, XXXIV (2015), pp. 157-168, ISSN: 0212-0429 
Si en la pieza de los dos azores no se recrea la pelea entre ellos, aunque sean rivales que comparten un mismo amor, en la relación de Alonso sí se produce una lucha, pero el poderío del águila conforma una ventaja con la que no puede competir el jilguero. El minimalismo con el que se describe el resultado no puede pertenecer a otro terreno que no sea la erudición culta, ya que las flores que antes semejaban con su color amarillo las alas del jilguero, ahora se encuentran manchadas de su sangre; también la delicadeza con la que se desarrolla este pasaje demuestra la sobriedad de nuestro poeta a la hora de manejar recursos tópicos en la lírica tradicional ${ }^{15}$. Tras la pelea de las dos aves, la tragedia inunda los versos que antes celebraban el amor y su acompañamiento natural, de una manera idéntica a como pasa en el final de El caballero de Olmedo.

No obstante, cuando parece que la visión que tiene tras la ventana va a llegar a su fin, Alonso nos relata la aparición de la esposa del jilguero, que escucha los gritos de su marido desde el jazmín donde ha sido testigo de esta lucha de amor. Ni que decir tiene que la aparición de este tipo de flor no es casual, pues su color blanco redunda en los valores de inocencia y de pureza que se le atribuyen a la Virgen María y, por ende, a la esposa del jilguero, que encarna al personaje de doña Inés ${ }^{16}$. Tanto el simbolismo del color del jazmín como la calidad disfrutada por el pájaro hembra que allí se posa reinciden en la pureza en el amor de Alonso, siempre orientado al casamiento, por lo que la necesidad que tiene este de Fabia, que presenta un carácter satánico sacado de La Celestina, sería para Doménech disculpable (1987: 106). En definitiva, el elemento vegetal del jazmín, en vez de remitirnos a la tradición popular, pretende conformar una imagen mariana de la mujer del jilguero que llora piadosamente su muerte, fundiéndose sus quejidos con los primeros rayos del amanecer mediante la suave personificación del aura, que responde con «débiles ecos» (vv. 1779-1780).

Falta por determinar, en última instancia, el motivo de la muerte del héroe, que desde tiempos medievales pertenece al folklore más arraigado, además de que

$\overline{15}$ De este aspecto se ocupan Ignacio Arellano y Juan Manuel Escudero en su edición de El caballero de Olmedo, afirmando que Lope de Vega «asimiló también toda la tradición popular: cancioneros, romanceros, refranes, todo el folclore y la vida del pueblo que formaba el público de su obra. Los elementos del Romancero y del cancionero tradicional son omnipresentes en su teatro, recogidos, adaptados, reinventados en sus comedias, que alcanzan, en buena parte por esta vía, un nivel lírico excepcional, perfectamente conciliado con las dimensiones puramente teatrales» (Vega Carpio 1998: 32).

16 El color blanco, junto con el azul, eran los colores utilizados para representar a la Madre de Dios, por lo que la ornamentación de los libros de horas suele plagarse de elementos florales de ambos colores. Para los tipos de flores y de animales que aparecen en los libros de horas de la colección de Lázaro Galdiano, véase Gómez Moreno (2011). Con respecto a las cualidades virtuosas del personaje de doña Inés, Sage comenta que encarna los atributos propios de una heroína porque «she is in all other respects honourable and virtuous» (Vega Carpio 1974: 53). 
para muchos críticos constituye la línea principal de esta tragicomedia ${ }^{17}$. Por ende, la muerte del amante que propicia los lloros de la dama también es un tópico compartido en la lírica tradicional; transcribo este poemita, que no tiene desperdicio, como colofón al cúmulo de relaciones señaladas:

\author{
Gritos daba la morenica \\ so el olivar, \\ que las ramas hace temblar. \\ La niña cuerpo garrido \\ lloraba su muerto amigo \\ so el olivar, \\ que las ramas hace temblar.
}

(Frenk 1987: 358)

En fin, hemos podido comprobar que la visión del jardín presenciada por Alonso conforma el tópico vergel de amores con significado alegórico, pues cada elemento presenta un sentido simbólico determinado. Los dos jilgueros que son pareja constituyen dos polos independientes según las convenciones del amor cortés, que apreciamos en parte gracias al significado que obtienen los elementos vegetales en la lírica tradicional. Más concretamente, mientras que la retama redunda en la amargura de amor sentida por el amante (por tanto, conforma el polo activo del hecho amoroso), el jazmín resalta tanto la virtud como la belleza de la amada, aspectos que reinciden en su apariencia física y moral y que hacen que le toque el papel pasivo de la relación (sería la meta a la que pretende llegar el amante con sus quejas en forma de canto) ${ }^{18}$. Por otra parte, el estilo, depurado y sencillo, contrasta con la poesía cancioneril, que apuesta por el hermetismo y la abstracción en el lenguaje (Whinnom 1981); y es que dicho estilo se caracteriza por la búsqueda de la naturalidad en el hecho teatral, donde el folklore y el sentir del pueblo, reflejados en los poemitas de índole popular, son sus mejores aliados.

Recibido: 2/05/2015

Aceptado: 27/07/2015

\footnotetext{
17 «Todo en El caballero de Olmedo converge, pues, en esta idea medular: el enfrentamiento del Caballero a la muerte, enfrentamiento que se anticipa desde el principio» (Doménech 1987: 109). Para Profeti también esta tragicomedia se fundamenta en el binomio amor-muerte (Vega Carpio 2002: 83).

18 Esta concepción de los dos polos en el amor cortés ha sido señalada por Profeti (Vega Carpio 2002: 78-81), aunque no se ha fijado en la premonición de Alonso para establecerla. En resumidas cuentas, considera que la mujer amada se encuentra «inmóvil y encerrada en un espacio delimitado», mientras que el hombre posee una mayor actividad porque se mueve por el exterior de ese espacio imaginario que intenta penetrar (Vega Carpio 2002: 81).
} 


\section{BIBLIOGRAFÍA}

Alín, José María (1968). El cancionero español de tipo tradicional. Madrid: Taurus.

Alonso, Dámaso (1964). De los siglos oscuros al de Oro. $2^{\mathrm{a}}$ ed. Madrid: Gredos.

Blecua, José Manuel (1970). Sobre poesía de la Edad de Oro. Madrid: Gredos.

CARreÑo, Antonio (1979). El romancero lírico de Lope de Vega. Madrid: Gredos.

Carvallo, Juan Alfonso de (1602). Cisne de Apolo. Medina del Campo: Juan Godínez de Millis.

Díez de Revenga, Francisco J. (1983). Teatro de Lope de Vega y lírica tradicional. Murcia: Universidad de Murcia.

DomÉNeCH, Ricardo (ed.) (1987). «El castigo sin venganza» y el teatro de Lope de Vega. Madrid: Cátedra.

Fournival, Richard de (1980). Bestiario de Amor. Traducción y edición de Ramón Alba. Madrid: Miraguano Ediciones.

Frenk Alatorre, Margit (1963). «Lope, poeta popular». Anuario de Letras, 3, pp. 253-266. (1987). Corpus de la antigua lírica popular hispánica (siglos xv a xvii). Madrid: Castalia (NBEC).

(2007). Del siglo de oro español. México D. F.: El Colegio de México. (ed.) (2010). Lírica española de tipo popular. $15^{\mathrm{a}}$ ed. Madrid: Cátedra.

Gómez Moreno, Ángel (2011). «Borduras y flores en los libros de horas de la Fundación Lázaro Galdiano». En Juan Antonio Yeves (dir.), Tiempo de Navidad. Los libros de horas de don José Lázaro Galdiano. Madrid: Fundación Lázaro Galdiano, pp. 161-175.

Green, Otis H. (1969). España y la tradición occidental. Carlos Sánchez Gil (trad.). Madrid: Gredos.

McGrady, Donald (1989). «Misterio y tradición en el romance del Prisionero». En Antonio Vilanova (ed.), Actas del X Congreso de la Asociación Internacional de Hispanistas. Barcelona: PPU, I, pp. 273-282.

Palomo, María del Pilar (1987). La poesía en la Edad de Oro (Barroco). Madrid: Taurus.

PedraZA JimÉNEZ, Felipe B. (2008). Lope de Vega: vida y literatura. Valladolid: Universidad de Valladolid.

Rodado Ruiz, Ana M. (2000). Tristura conmigo va. Fundamentos de Amor Cortés. Cuenca: Universidad de Castilla-La Mancha.

RodrígueZ MoÑIno, Antonio (ed.) (1957). Las fuentes del Romancero General (Madrid, 1600). 12 vols. Madrid: Real Academia Española.

(ed.) (1967). Cancionero de romances (Anvers, 1550). Madrid: Castalia.

Rojas, Fernando de (2008). La Celestina. Comedia o tragicomedia de Calisto y Melibea. Edición de Peter E. Russell, $3^{\text {a }}$ ed. Madrid: Castalia.

Rozas, Juan Manuel (1990). Estudios sobre Lope de Vega. Edición de Jesús Cañas Murillo. Madrid: Cátedra.

TORner, Eduardo M. (1966). Lírica hispánica. Relaciones entre lo popular y lo culto. Madrid: Castalia.

Vega CARPIO, Lope de (1974). El caballero de Olmedo. Edición de Jack W. Sage. Londres: Tamesis Books Ltd. 
Vega CARPIO, Lope de (1989). La dama boba. Edición de Diego Marín, $15^{\mathrm{a}}$ ed. Madrid: Cátedra.

(1998). El caballero de Olmedo. Edición de Ignacio Arellano y Juan M. Escudero. Madrid: Espasa-Calpe.

(2002). Fuenteovejuna. El caballero de Olmedo. Edición de Maria G. Profeti. Madrid: Biblioteca Nueva.

- (2011). El caballero de Olmedo. Edición de Francisco Rico. 25ª ed. Madrid: Cátedra. (2012a). Arcadia, prosas y versos. Edición de Antonio Sánchez Jiménez. Madrid: Cátedra.

(2012b). Arte nuevo de hacer comedias. Edición de Enrique García Santo-Tomás. $3^{\text {a }}$ ed. Madrid: Cátedra.

Whinnom, Keith (1981). La poesía amatoria de la época de los Reyes Católicos. Kendal (Cumbria): Universidad de Durham.

Zamora Vicente, Alonso (1986). Una mirada a lo popular en el teatro de Lope de Vega. Madrid: Cátedra. 
la visión premonitoria de Alonso en El caballero de Olmedo: otra recuperación de lo popular

Resumen: Si bien son conocidas las filiaciones de la lírica tradicional en el teatro lopesco, todavía hay mucho camino por recorrer a la hora de establecerlas. En esta perspectiva se mueve el presente trabajo, pues plantea el estudio del sueño de Alonso de El caballero de Olmedo desde la vertiente popular. Solo de esta manera puede entenderse el sueño como una representación trágica del amor frustrado entre Alonso e Inés: desde una relectura de la secuencia según las imágenes de origen tradicional.

Palabras clave: Lope de Vega, lírica tradicional, sueño, jilguero, azor, retama, azucena.

\section{Alonso 's premonitory vision in El caballero de Olmedo: another retrieval of the} traditional lyric

ABSTRACT: Although it is known that Lope's plays have some connections to the traditional lyric, there's still too much work to do. From this perspective the present work moves, as it considers the study of the dream of Alonso, character of El caballero de Olmedo, from the popular side. Only in this way this dream is understandable like a tragic representation of the frustrated love between Alonso and Ines: from a reading of the sequence according to the images with a traditional origin.

KEYwORDS: Lope de Vega, traditional lyric, dream, goldfinch, goshawk, broom, madonna lily. 
TERESA DE JESÚS (1515-1582)

Guillermo Serés (Universidad Autónoma de Barcelona)

La imaginación de Santa Teresa: virtudes y desatinos de «la loca de la casa»....... 11

Ana Garriga EsPino (Universidad Autónoma de Madrid)

El desafío editorial de las cartas de Teresa de Jesús.

LeCTURAS REPUBLICANAS DEL QUIJOTE

RAQUEL ArIas (Universidad Autónoma de Madrid)

León Felipe alista a don Quijote en el bando republicano. 57

MANUEl LóPez ForJas (Universidad Autónoma de Madrid)

El Quijote y la realidad viva de las Españas: la visión histórica

de Pedro Bosch-Gimpera.

CArmen Madorrán Ayerra (Universidad Autónoma de Madrid)

El Quijote como utopía necesaria: la mirada de Adolfo Sánchez Vázquez 85

\section{OTROS TEMAS}

SònIA BoADAS (Universitat Autònoma de Barcelona)

Libros y librerías: la recepción de Commynes en España 101

Lucila Lobato Osorio (Universidad Nacional Autónoma de México)

La noticia de la muerte de Policisne de Boecia: expresiones de dolor en un libro inconcluso.

María Gutiérrez Padilla (Universidad Nacional Autónoma de México)

La escenografía en el teatro caballeresco 131

ADRIÁn FERnÁNDEZ (Université de Fribourg)

Dos entremeses «auditivos» y sus niveles: hacia un metateatro visual. 145

David González de la Higuera Garrido (Universidad Complutense de Madrid) La visión premonitoria de Alonso en El caballero de Olmedo:

otra recuperación de lo popular

Esther Fernández LóPEz (UNED)

Perseo en la comedia tardobarroca: Ignacio Ferrera y Pasqual 169

Manuel Piqueras Flores (Universidad Autónoma de Madrid)

De La hija de Celestina $a$ La ingeniosa Elena: estructura narrativa, género literario e interpolación 
Dagoberto CÁceres Agullar (Western University Canada)

Realismo incesante: desde Celestina hacia su recepción 201

TeXTOS INÉDITOS

Davinia Rodríguez Ortega (Universidad Pública de Navarra)

Auto sacramental del Juego del Hombre, de Luis Mejía de la Cerda:

edición crítica 


\section{EDAD DE ORO}

Revista de Filología Hispánica XXXIV

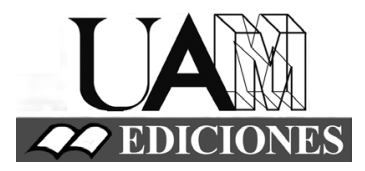




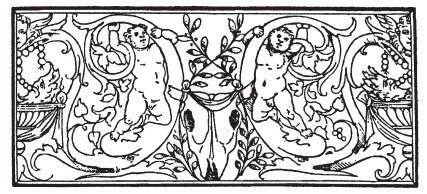

\section{Edad de Oro. Revista de Filología Hispánica}

ISSN: 0212-0429

Dirección:

Teodosio Fernández

Secretaría y edición:

José Ramón Trujillo

Comité científico internacional:

Carlos Alvar (Univ. de Ginebra)

Ignacio Arellano (Univ. de Navarra)

Javier Blasco (Univ. de Valladolid)

Alberto Blecua (UAB)

Jean Canavaggio (Univ. de París X)

Laura Dolfi (Univ. de Turín)

Aurora Egido (Univ. de Zaragoza)

Víctor García de la Concha (RAE)

Luciano García Lorenzo (CSIC)

Joaquín González Cuenca (Univ. de Castilla-

La Mancha)

Agustín de La Granja (Univ. de Granada)

Begoña López Bueno (Univ. de Sevilla)

Michel Moner (Univ. de Toulouse III)

Joan Oleza (Univ. de Valencia)

Alfonso Rey (Univ. de Santiago)

Lina Rodríguez Cacho (Univ. de Salamanca)

Leonardo Romero Tobar (Univ. de Zaragoza)

Aldo Ruffinatto (Univ. de Turín)

Lía Schwartz (City University of New York)
Redacción y admisión de originales:

Teodosio Fernández

Edad de Oro

Departamento de Filología Española

Universidad Autónoma de Madrid

28049 Madrid (España)

Tfno.: +0034914974090

correo: teodosio.fernandez@uam.es

Distribución, suscripción y venta:

Servicio de Publicaciones de la UAM

Universidad Autónoma de Madrid

28049 Madrid (España)

Intercambio de publicaciones:

Biblioteca de la Facultad de Filosofía y

Letras (UAM)

Universidad Autónoma de Madrid

28049 Madrid (España)

Han colaborado en este volumen:

Departamento de Filología Española (UAM)

Facultad de Filosofia y Letras (UAM)

Edad de Oro se recoge, entre otras, en las siguientes bases de datos: SCOPUS, MLA Database, HLAS, Latindex, PIO-Periodical Content Index, ISOC, Dialnet, MIAR, ERIH, DICE, Sumaris CBUC, Ulrich's. Se encuentra evaluada en CIRC: A; INRECH; MIAR difusión ICDS live: 9.977; SCImago Journal \& Country Rank: H Index 2, SJR 0,101, Q4; RESH índice de impacto: 0.041; ERIH: A INT1; Carhus Plus+ 2014: C. 